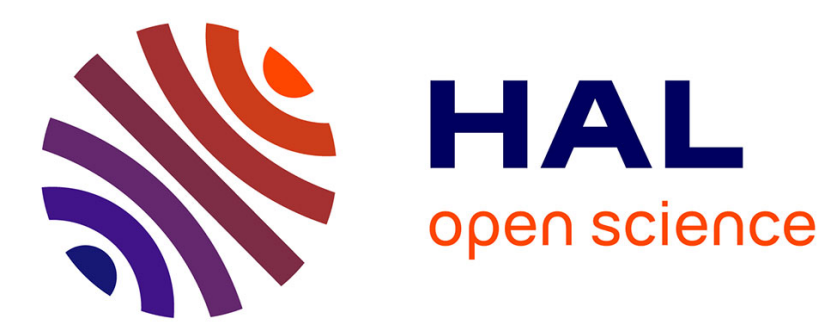

\title{
On the relationship between the basicity of a surface and its ability to catalyze transesterification in liquid and gas phases: the case of $\mathrm{MgO}$
}

Damien Cornu, Hazar Guesmi, Guillaume Laugel, Jean-Marc Krafft, Hélène Lauron-Pernot

\section{To cite this version:}

Damien Cornu, Hazar Guesmi, Guillaume Laugel, Jean-Marc Krafft, Hélène Lauron-Pernot. On the relationship between the basicity of a surface and its ability to catalyze transesterification in liquid and gas phases: the case of MgO. Physical Chemistry Chemical Physics, 2015, 17, pp.14168-14176 10.1039/C5CP00217F . hal-01153367

\section{HAL Id: hal-01153367 \\ https://hal.sorbonne-universite.fr/hal-01153367}

Submitted on 19 May 2015

HAL is a multi-disciplinary open access archive for the deposit and dissemination of scientific research documents, whether they are published or not. The documents may come from teaching and research institutions in France or abroad, or from public or private research centers.
L'archive ouverte pluridisciplinaire HAL, est destinée au dépôt et à la diffusion de documents scientifiques de niveau recherche, publiés ou non, émanant des établissements d'enseignement et de recherche français ou étrangers, des laboratoires publics ou privés. 
On the relationship between the basicity of a surface and its ability to catalyze transesterification in liquid and gas phases: the case of $\mathrm{MgO}$

Damien Cornu $^{1,2 \#} *$, Hazar Guesmi ${ }^{1,2+}$, Guillaume Laugel ${ }^{1,2}$, Jean-Marc Krafft ${ }^{1,2}$, Hélène Lauron-Pernot ${ }^{1,2 *}$

${ }^{1}$ Sorbonne Universités, UPMC Univ Paris 06, UMR 7197, Laboratoire de Réactivité de Surface, 3 rue Galilée F-94200, Ivry sur Seine, France

2 CNRS, UMR7197, Laboratoire de Réactivité de Surface, 3 rue Galilée F-94200, Ivry sur Seine, France

*cornu.damien@laposte.net, helene.pernot@upmc.fr

\section{Abstract}

Gas or liquid phase transesterification reactions are used in the field of biomass valorization to transform some platform molecules into valuable products. Basic heterogeneous catalysts are often claimed for these applications but the role of basicity on the reaction mechanism depending on the operating conditions is still under debate. In order to compare the catalyst properties necessary to perform a transesterification reaction both in liquid and gas phases, ethyl acetate and methanol, that can be easily processed both in these two phases, were chosen as reactants. The catalyst studied is $\mathrm{MgO}$, known for its basic properties and its ability to perform the reaction. By means of appropriate thermal treatments, different kinds of $\mathrm{MgO}$ surfaces, with different coverage of natural adsorbates (carbonates and hydroxyl groups) can be prepared and characterized by means of $\mathrm{CO}_{2}$ adsorption followed by IR spectroscopy and hept-1-ene isomerization model reaction. New results on the basicity of natural $\mathrm{MgO}$ surface (covered by carbonate and hydroxyl groups) are first given and discussed. The catalytic behavior in transesterification reaction is then determined as a function of the Present addresses:

\# Fritz-Haber-Institut der MPG, Department of Chemical Physics, Faradayweg 4-6, 14195 Berlin, Germany + CNRS-Institut Charles Gerhardt, UMR 5253, équipe MACS, 8 rue de 1'Ecole Normale 34296, Montpellier, France 
adsorbates coverage. It is shown that the transesterification activity in the liquid phase is directly correlated to the kinetic basicity of the surface in agreement with the mechanism already proposed in the literature. On the reverse, no direct correlation with the basicity of the surface was established with the transesterification activity in gas phase. A very high activity, in gas phase was observed and discussed for the natural surface pre-treated at $623 \mathrm{~K}$. Preliminary DFT modeling of ester adsorption and methanol adsorption capacity determination were performed to investigate plausible reaction routes.

\section{Introduction}

The heterogeneous catalysis of transesterification is a very trendy topic due to the utilization of this reaction to transform triglycerides into biodiesel. ${ }^{[1]}$ However, this reaction can also be used through gas or liquid phase processes for the production of other molecules of industrial interest: different kinds of organic carbonates, ${ }^{[2]}$ levulinate by way of the opening of lactones, ${ }^{[3]}$ some polyesters from polyols and organic carbonates $^{[4]}$ or from lactones. ${ }^{[5]}$

Numerous basic solids, especially alkaline earth oxides, are known to catalyze transesterification in the liquid phase and it has often been claimed that the more basic the surface, the better the catalyst. ${ }^{[6-9]}$ Nevertheless, in most of these publications, the basicity of the catalyst is investigated by means of the desorption of a Lewis acid $\left(\mathrm{CO}_{2}\right)$ followed by $\mathrm{TPD}^{[10,11]}$ or IR spectroscopy ${ }^{[12]}$. But this method gives insights on the interaction of a Lewis acid $\left(\mathrm{CO}_{2}\right)$ with the surface, that may not correlate with the ability of the same surface to efficiently deprotonate a Brønsted acid. ${ }^{[13]}$ For example, Veiga et $a l .{ }^{[14]}$ and Kozlowski et al. ${ }^{[15]}$ didn't find any correlation between the adsorption of $\mathrm{CO}_{2}$ (and, therefore, Lewis basicity) and the catalyst reactivity in the 
transesterification reaction. In the latter, $\mathrm{Zr}$ clearly plays a role on methanol deprotonation as expected for a Lewis acid that may increase Brønsted basicity. ${ }^{[15]}$ The improvement of reactivity due to $\mathrm{Zr}$ could be in line with the mechanism proposed by Dossin et al. ${ }^{[16]}$ that identifies the adsorption of the alcohol as a rate determining step in the specific case of the reaction between methanol and ethyl acetate in the liquid phase. We propose in Scheme 1 a representation of such a mechanism involving the deprotonation of the alcohol.

Other publications still find a correlation between the reactivity in the transesterification reaction and the Brønsted basicity, measured with the adsorption of methanol followed by IR spectroscopy, ${ }^{[17]}$ with Hammett indicators, ${ }^{[1,18]}$ or probed with DFT modeling. ${ }^{[19]}$ However, Hattori et al. have shown that the order of reactivity of various oxides in transesterification catalysis depends on the nature of the alcohol and not only with basicity of the catalyst. ${ }^{[20]}$ Moreover, materials with an apparent weak basicity can also catalyze efficiently this reaction, like alkaline earth carbonates for ring-opening of lactones. ${ }^{[21]}$

Basicity can also be evaluated by model reactions that probe a "kinetic basicity" (the rate of a reaction on a basic site) which may differs from the thermodynamic basicity given by equilibrium adsorption of probe molecules (as studied by the methods mentioned above $)^{[22]}$. To our knowledge, the correlation between this basicity and the reactivity in transesterification reaction was never studied and may explain some of the discrepancies described in the literature.

The aim of this study is to better define the catalyst properties necessary to perform a transesterification reaction both in liquid and gas phases. In order to compare the results obtained in both phases on the same catalyst and for similar pretreatments, 
light ester and alcohol (ethyl acetate and methanol) were chosen as reactants, with a boiling point at atmospheric pressure close to the room temperature.

Magnesium oxide was used as a catalyst, because it is a promising catalyst for transesterification $^{[23,24]}$ as well as a solid, which surface structure and reactivity have been extensively studied. ${ }^{[25-27]}$. The effect of the two natural adsorbates (hydroxyl groups and carbonates) on the basic reactivity of $\mathrm{MgO}$ is now better known through previous mixed experimental and theoretical work carried out on purely hydroxylated and carbonated surfaces ${ }^{[28,29]}$ using $\mathrm{CO}_{2}$ adsorption followed by IR spectroscopy, 2methyl-3-butyn-2-ol (MBOH) conversion and hept-1-ene isomerization as model reactions of basicity.

We first investigated here the basicity of the natural $\mathrm{MgO}$ surface obtained by direct thermal treatment (covered both by hydroxyl and carbonate groups), that was never considered, by means of $\mathrm{CO}_{2}$ adsorption followed by IR spectroscopy and hept-1ene isomerization. Based on this good knowledge of $\mathrm{MgO}$ surface, the transesterification catalytic data, in gas and liquid phases are correlated to $\mathrm{MeOH}$ adsorption capacity measurements. The results are discussed in terms of nature and properties of the active sites. The different behavior of the catalysts observed in liquid and gas phases lead us to a discussion about the nature of the reaction intermediates. As the reaction mechanism has, to our knowledge, never been investigated in gas phase, we performed preliminary DFT calculations to give some insights on the plausible nature of reaction intermediates.

\section{Experimental section}

\subsection{Preparation and pretreatment of the catalyst}




\subsubsection{Synthesis of $\mathrm{MgO}$ from $\mathrm{Mg}(\mathrm{OH})_{2}$}

$\mathrm{MgO}$ samples were prepared from $\mathrm{Mg}(\mathrm{OH})_{2}$ precursor obtained by precipitation from $\mathrm{Mg}\left(\mathrm{NO}_{3}\right)_{2}$ (Aldrich, 99.99\%) and ammonium hydroxide (Aldrich, 99\%) as precipitating agent, according to a previously described procedure. ${ }^{[30]}$ The hydroxide sample was finally treated in vacuum $\left(<1\right.$ Torr) up to $1273 \mathrm{~K}\left(\operatorname{ramp} 1 \mathrm{~K} \cdot \mathrm{min}^{-1}\right)$ and maintained at this temperature for $2 \mathrm{~h}$ to obtain stable magnesium surface $\left(150 \mathrm{~m}^{2} \cdot \mathrm{g}^{-1}\right)$. This procedure is used to stabilize the $\mathrm{MgO}$ surface towards the effect of further thermal treatments, as shown in our previous publications ${ }^{[29]}$.

\subsubsection{Pretreatments of the $\mathrm{MgO}$ surfaces}

Natural surfaces of $\mathrm{MgO}$ at "temp": before any gas phase catalytic study, the sample was cleaned up for $2 \mathrm{~h}$ at a defined temperature called "temp" under nitrogen flow (Air Liquide, $>99.995 \%$ pure) $\left(20 \mathrm{~cm}^{3} \cdot \mathrm{min}^{-1}\right)$, then cooled down to the reaction temperature. For the liquid phase, a similar pretreatment was achieved in a U quartztube that can be closed by two valves and then transferred in a Schlenk flask for the reaction under argon atmosphere through a glove box. In this case, depending on the pretreatment temperature, the surface is covered by both hydroxyl groups and carbonates.

Hydroxylated and carbonated surfaces of $\mathrm{MgO}$ at "temp": the preparation of the surface covered only with hydroxyl groups (hydroxylated surfaces) or only with carbonates (carbonated surfaces) is described in a previous work. ${ }^{[29]}$ The two first steps consist in treating the sample at high temperature $(1023 \mathrm{~K})$ to clean the surface and in adding water (or carbon dioxide) at low temperature to create new adsorbates. The amount of hydroxyl groups (or carbonates) on the surface is monitored by the last step of the pretreatment, which requires a heating up to a temperature "temp". 


\subsection{Alkene isomerization and transesterification in gas phase}

Transesterification and alkene isomerization were processed in an automated microreactor. For each experiment, $40 \mathrm{mg}$ of catalyst was deposited on porous glass, in the center of a $10 \mathrm{~mm}$-i.d. U quartz tube and pretreated according to the procedure described earlier (2.1). The reaction temperature $(333 \mathrm{~K})$ for both reactions was controlled within $\pm 0.1 \mathrm{~K}$ by a thermocouple located near the catalyst. In both cases, the reactants were introduced by means of a liquid mass flow meter (Bronkhorst liquid mass flow controller), mixed and vaporized in a gas flow of nitrogen (Air liquide 99.995\%), introduced through a Bronkhorst gas mass flow controller. Flow rate for nitrogen was kept at $45 \mathrm{~cm}^{3} \cdot \mathrm{min}^{-1}$.

For the transesterification, methanol (Sigma Aldrich anhydrous 99.8\%) and ethyl acetate (Sigma Aldrich anhydrous 99.8\%) were premixed and introduced with a molar ratio of 24.25 . The liquid flow rate was $0.225 \mathrm{~g} \cdot \mathrm{h}^{-1}$ for the mixture. Therefore, the partial pressure of methanol in the reactor is $55.8 \mathrm{~Pa}$ and the partial pressure of ethyl acetate is $2.42 \mathrm{~Pa}$. The first analysis was carried out $180 \mathrm{~s}$ after the introduction of the mixture on the sample.

For alkene isomerization, flow rate of hept-1-ene (Acros Organics 98\%) was 0.3 g.h ${ }^{-1}$ (partial pressure of 31 mbar). The first analysis was performed $120 \mathrm{~s}$ after the contact of the alkene flow on the sample.

Reaction products were analyzed every $366 \mathrm{~s}$ (alkene isomerization) or $486 \mathrm{~s}$ (transesterification) using a Varian chromatograph equipped with a FID detector and a CP WAX 57 CB column.

The hept-1-ene was converted into $\mathrm{Z}$ and $\mathrm{E}$ hept-2-ene with an average ratio of $\mathrm{Z}$ 
hept-2-ene/E hept-2-ene around 2 (a typical value for basic catalysts), ${ }^{[29]}$ that did not vary in the different experiments. Ethanol and methyl acetate are the only products detected for the transesterification thus catalytic data are expressed for both reactions in terms of conversion only. The partial pressure of each reactant $\mathrm{Pi}^{\circ}$ (before reaction) and Pi (after reaction) was calculated from chromatographic measurements using the appropriate response coefficient. The conversion $\tau$ is given by equation 1 .

$$
\tau=\frac{\mathrm{P}_{\mathrm{i}}^{\circ}-\mathrm{P}_{\mathrm{i}}}{\mathrm{P}_{\mathrm{i}}^{\circ}}
$$

Eq. 1: Calculation of the conversion in gas phase

where i stands for hept-1-ene for isomerization and ethyl acetate for transesterification.

Carbon balance is systematically checked and is always determined at values over $95 \%$.

\subsection{Transesterification in liquid phase}

$40 \mathrm{mg}$ of the catalyst previously pretreated was introduced in a Schlenk flask under Argon atmosphere in a glove box. Vacuum conditions were then established in the Schlenk flask through a vacuum manifold $\left(10^{-3}\right.$ Torr $)$ and then the Schlenk was heated in an oil bath at $343 \mathrm{~K}$. One hour later, nitrogen (Air liquide 99.99\%) was introduced into the Schlenk (1 bar) and then $10 \mathrm{~mL}$ methanol (Sigma Aldrich anhydrous 99.8\%) and $1 \mathrm{~mL} \mathrm{1,4} \mathrm{dioxane} \mathrm{(Sigma} \mathrm{Aldrich} \mathrm{anhydrous} \mathrm{99.8 \% ),} \mathrm{as} \mathrm{standard} \mathrm{reference,}$ were introduced through needles into the Schlenk. The introduction of $1 \mathrm{~mL}$ ethyl acetate (Sigma Aldrich anhydrous 99.8\%) determines the initial time of the reaction. Like in the gas phase, the molar ratio between the reactants was 24.25. 
The ratios ethyl acetate/dioxane, methyl acetate/dioxane, ethanol/dioxane, and methanol/dioxane were determined by gas chromatography of a sample taken from the Schlenk and diluted in n-butanol after 5 hours of reaction. The only detected products were methyl acetate and ethanol, therefore the conversion was calculated through equation 2:

$$
\tau=\frac{\frac{\text { AcOEt }}{\text { Dioxanne }} \mathrm{t}=0 \text { AcOEt }}{\frac{\text { AcOEt }}{\text { Dioxanne }} \mathrm{t}=5 \mathrm{~h}}
$$

Eq. 2: Calculation of the conversion in liquid phase

\subsection{Infra-red spectroscopy}

Infrared spectra were obtained from self-supported pellets $(30 \mathrm{mg})$ placed in a quartz cell equipped with $\mathrm{CaF}_{2}$ windows and connected to a vacuum line allowing thermal treatments and adsorption-desorption experiments to be carried out in situ. Wafers were first pretreated in vacuum at the pretreatment temperature during 2 hours, then cooled down to room temperature. Therefore, only natural surfaces were studied. Spectra were recorded (at room temperature) before and after introduction at room temperature of increasing doses of $\mathrm{CO}_{2}$ gas (a dose consisting in a small volume -1.2 $\mathrm{cm}^{3}$ filled with $8.4 .10^{-8} \mathrm{~mol}$ of $\mathrm{CO}_{2}$ ) up to a final equilibrium pressure of 0.8 Torr using a Bruker FTIR Vector 22 spectrometer, equipped with an MCT detector (resolution 2 $\mathrm{cm}^{-1}, 128$ scans per spectrum). The spectra of adsorbed molecules are reported in absorbance by subtracting the spectrum before adsorption to the spectrum after.

\subsection{Dynamic adsorption on the catalyst}


A mass spectrometer (OmniStar GSD 320, Pfeiffer vacuum) analyses every second the concentration of methanol (Sigma Aldrich anhydrous 99.8\%) through the peak $\mathrm{m} / \mathrm{q}=32$ in a flow composed of methanol $\left(0.75 \mathrm{~g} \cdot \mathrm{h}^{-1}\right)$ and nitrogen $\left(45 \mathrm{~mL} \cdot \mathrm{min}^{-1}\right)$. The flow is then redirected on a micro-reactor containing either $40 \mathrm{mg}$ of catalyst after pretreatment or nothing (blank analysis). The total adsorbed amount of methanol on the catalyst is given by the difference between the integration of the signal $\sigma$ obtained with magnesium oxide and the blank signal $\sigma_{0}$ as shown by equation 3 .

$$
\Sigma_{a d s}={ }_{0}^{\tau} \sigma-\sigma_{0} d t
$$

Eq. 3: Measurement of the amount of adsorbed methanol on $\mathrm{MgO}$

Knowing the signal $\sigma_{0}$ for the continuous methanol flow $\left(0.75 \mathrm{~g} \cdot \mathrm{h}^{-1}\right)$, the quantity $\Sigma_{\text {ads }}$ can be converted in an absolute quantity and divided by the mass of the catalyst.

\subsection{Computational details}

DFT calculations were performed using ab-initio plane-wave pseudopotential approach as implemented in VASP. ${ }^{[31,32]}$ The generalized gradient approximation exchange-correlation functional of Perdew and Wang PW91 ${ }^{[33]}$ was chosen to perform the periodic calculations with reliable accuracy. The convergence criterion for the electronic self-consistent cycle was fixed to $10^{-6} \mathrm{eV}$ per supercell. Geometry optimizations were performed within a conjugate-gradient algorithm until the convergence criterion on forces $\left(10^{-2} \mathrm{eV} . \AA^{-1}\right)$ was reached. A dipolar correction along the perpendicular to the slab was applied in order to remove the effect of electrostatic interaction between the slab and its periodic images along the $\mathrm{z}$ axis. 
The adsorption energy of ester on the $\mathrm{MgO}$ surfaces was calculated as:

$$
\mathrm{E}_{\text {ads }}(0 \mathrm{~K})=\mathrm{E}_{\text {ester/surf }}-\left(\mathrm{E}_{\text {surf }}+\mathrm{E}_{\text {free-ester }}\right)
$$

Eq. 4: Adsorption energy of the ester

Where $\mathrm{E}_{\text {surf }}$ represents the energy of bare surface, $\mathrm{E}_{\text {free-ester }}$ is the energy of gas ester and $\mathrm{E}_{\text {ester/surf }}$ that of the adsorbed system.

The $\mathrm{MgO}$ surface is represented by the monoatomic step (S1) models already used in our previous works. ${ }^{[34,35]}$ This $\mathrm{MgO}$ surface defect involves four coordinated (4C) ions and is composed by three-layer slab representing a 1- $\mathrm{d}_{\mathrm{Mg}-\mathrm{O}}$ high step with a 6$\mathrm{dMg}-\mathrm{O}$ long edge (where $\mathrm{d}_{\mathrm{Mg}-\mathrm{O}}$ is the $\mathrm{Mg}-\mathrm{O}$ distance). It offers three available $\mathrm{Mg}-\mathrm{O}$ sites for the adsorption of molecules water, ${ }^{[36]} \mathrm{CO}_{2}{ }^{[13]}$, or alcohol. ${ }^{[35]}$ The two upper layers of the slab were allowed to relax during all the calculations.

\section{Results and discussion}

3.1. Structure and basic reactivity of the $\mathrm{MgO}$ natural surface

\subsubsection{Background on hydroxylated and carbonated surfaces}

As mentioned in our previous publication, ${ }^{[29]}$ the specific surface area of the materials remains unaffected after a hydroxylation or a carbonatation cycle in agreement with the similar hept-1-ene conversion obtained before and after a complete desorption cycle. On figure 1 is reported the conversion of hept-1-ene on magnesium oxide as a function of the pretreatment temperature ("temp") for the following surfaces:

- Heated at high temperature $(1023 \mathrm{~K})$, covered with water at low temperature then heated again at temp under nitrogen flow: hydroxylated surface 
- Heated at high temperature $(1023 \mathrm{~K})$, covered with $\mathrm{CO}_{2}$ at low temperature then heated again at temp under nitrogen flow: carbonated surface

- Directly treated at a given pretreatment temperature, temp (natural surface).

For carbonated surfaces (figure 1, solid line), a simple poisoning effect of the basic reactivity towards alcohol and alkene was observed ${ }^{[29]}$. In this case, the reactivity occurs only after carbonates desorption from the active sites.

In the case of hydroxylated surfaces (figure 1, dashed line), a maximum of reactivity is observed in the isomerization of hept-1-ene into the more stable configurations E-hept-2-ene and Z-hept-2-ene for intermediate pretreatment temperature (773 K). This phenomena could be explained through a well-known local restructuration happening during hydroxylation ${ }^{[26,37]}$ leading to the formation of (110) planes on $\mathrm{MgO}$, stabilized through the presence of hydroxyl groups on hydroxylated surfaces. These unstable planes have been shown to exhibit a high Brønsted basicity than the usual defects found on stable (100) planes. For example, the calculated adsorption energy of but-1-ene on the (110) surface is $0.32 \mathrm{eV}$ and $0.08 \mathrm{eV}$ on the (100) terrace. ${ }^{[29]}$ They are progressively unveiled by the desorption of hydroxyl groups with the increase of the pretreatment temperature. Nevertheless, at high temperature treatment, the unstable (110) planes disappear forming the more stable (100) planes and leading to a decrease of basic reactivity.

The formation of these (110) planes was evidenced through the adsorption of $\mathrm{CO}_{2}$ followed by IR spectroscopy ${ }^{[13]}$. Indeed, it has been shown that carbonates formed on the (100) surface (bidentate and tridentate) have a high splitting between the high $\left(v_{3 \mathrm{~h}}\right)$ and low $\left(v_{31}\right)$ vibration frequencies $\left(\Delta v>300 \mathrm{~cm}^{-1}\right)$ while carbonates adsorbed on the (110) planes exhibit a more symmetric structure and their vibration frequencies are 
closer to those observed for the isolated carbonate ${ }^{[38]}$ with a small splitting of the $v_{3}$ frequencies $\left(\Delta v<200 \mathrm{~cm}^{-1}\right)$.

\subsubsection{Infra-red study of adsorption of $\mathrm{CO}_{2}$ on $\mathrm{MgO}$ natural surface}

This method has thus been used to analyze the natural surface of $\mathrm{MgO}$ for various the pretreatment temperature. Figure 2 reports the FTIR spectra obtained after the addition of $14 \mu \mathrm{mol}$ (figure 2.a) and $56 \mu \mathrm{mol}$ (figure 2.b) of $\mathrm{CO}_{2}$ per gram of catalyst directly pretreated at $773 \mathrm{~K}$ and $1023 \mathrm{~K}$ in vacuum.

On figure 2.a, the difference between the sample treated at $773 \mathrm{~K}$ and the one treated at $1023 \mathrm{~K}$ is evidenced. For the sample pretreated at lower temperature, the bands with large split $\left(v_{3 \mathrm{~h}}>1600 \mathrm{~cm}^{-1}\right.$ and $\left.v_{31}<1350 \mathrm{~cm}^{-1}\right)$ that were attributed to tridentate and bidentate carbonates on a (100) surface $^{[13]}$ are much less intense than the bands in the central zone, between 1350 and $1600 \mathrm{~cm}^{-1}$ attributed to the carbonates on (110) planes. The sample pretreated at $1023 \mathrm{~K}$ shows a different proportion of those bands, with a much higher contribution of the carbonates on the (100) surface and a much lower one on the (110). This evolution could be linked to surface reconstruction and will be discussed for understanding the differences of the reactivity of those samples. Figure 2.b shows that, for larger quantity of $\mathrm{CO}_{2}$, the two spectra are very similar as the molecules are then mainly adsorbed on the less basic but more abundant sites located on the (100) plane. Saturation of the defects and therefore no further evolution of the IR signal is observed after the addition about of $\mathrm{CO}_{2} 150 \mu \mathrm{mol} . \mathrm{g}^{-1}$.

\subsubsection{Basic reactivity of magnesium oxide natural surfaces.}

On figure 1 (dotted line) is reported the conversion of hept-1-ene on magnesium oxide as a function of the pretreatment temperature ("temp") for natural surfaces. For a 
pretreatment temperature below $623 \mathrm{~K}$, that is to say for magnesium oxide with a huge coverage of hydroxyl groups and carbonates, there is no conversion of hept-1-ene.

At higher temperature $(1023 \mathrm{~K})$, the conversion is the same as the one obtained for the same pretreatment temperature on surface with only hydroxyl groups or carbonates, within the reproducibility of those measures $( \pm 3 \%$ ) (figure 1$)$. For an intermediate pretreatment temperature, the conversion profile shows a maximum (around $773 \mathrm{~K}$ ) but the level of conversion reached is much higher (more than 50\%) for natural surfaces than for the surface only covered with hydroxyl groups with similar temp values (lower than 25\%).

As mentioned in the 3.1.1 section, hydroxyl groups and carbonates poison the basic active sites. Infrared analysis (Section 3.1.2) has shown that the highly basic (110) planes are more abundant for the sample pretreated at $773 \mathrm{~K}$ than for the one pretreated at $1023 \mathrm{~K}$. Therefore, the increased reactivity at intermediate temperature can be explained by the temporary stabilization of (110) planes exposed to adsorbates, as it was already mentioned for the hydroxylated surfaces.

However, the conversion of hept-1-ene given by the natural surface pretreated at $773 \mathrm{~K}$ is much higher than the one obtained on the hydroxylated surface for the same temp value. As the carbonate is surely not responsible for the increased reactivity by itself, this enhanced reactivity has to be explained by the development on natural magnesium oxide covered by water and carbon dioxide of transient (110) planes in higher amount than on the hydroxylated surfaces. Indeed, natural surface has a much longer period of time to relax the exposed planes during exposure to water and $\mathrm{CO}_{2}$ than the hydroxylated $\mathrm{MgO}$ (a few hours in air between synthesis and use in catalysis, compared to 10 minutes of exposition to water for the later) and the conversion of the 
(100) planes into the (110) planes is kinetically slow. ${ }^{[26,39]}$. Therefore, the surface reconstruction is deeper for the natural surface, which explains the higher basic reactivity.

\subsection{Transesterification of ethyl acetate with methanol}

\subsubsection{Background}

The link between the pretreatment of $\mathrm{MgO}$ and its ability to catalyze liquid phase transesterification is still a matter of discussion. Leclercq and coworkers ${ }^{[40]}$ found that increasing the calcination temperature of magnesium oxide from 723 to $823 \mathrm{~K}$ leads to a significant improvement in the kinetics for the transesterification of fatty esters in liquid phase. More recently, $\mathrm{Xu}$ et $a l^{[24]}$ showed that the calcination of $\left(\mathrm{MgCO}_{3}\right)_{4} \cdot \mathrm{Mg}(\mathrm{OH})_{2}$ is optimum between 823 and $973 \mathrm{~K}$ to give the best activity in transesterification reaction. They related this phenomenon to an optimum of the surface area (which decreases for higher temperature, once $\left(\mathrm{MgCO}_{3}\right)_{4} \cdot \mathrm{Mg}(\mathrm{OH})_{2}$ is transformed into $\mathrm{MgO}$ ) and of the porous diameter (which should be large enough to ensure the migration of fatty ester). However, they assume that other characteristics, as the surface basicity, could be taken into account to explain this phenomenon. Recently, Di Cosimo et $a l$. have explained the lower reactivity of magnesium oxide calcined at high temperature by the diminution of the strong basic sites density on the surface during calcination. $^{[27]}$

In our study, the catalyst was first treated at high temperature to ensure that the specific surface area doesn't vary with a pretreatment cycle. The main transformation upon heating should be the coverage by hydroxyl groups and carbonates as well as the reconstruction of accessible planes that are unstable when uncovered. The results obtained here for hept-1ene isomerization on natural surfaces or previously reported for 
hydroxylated and carbonated surfaces show that the effect of surface reconstruction on catalysis is not detectable for the carbonated surface, effective for the hydroxylated one and huge for the natural surface. These results may enlighten those obtained for transesterification in gas and liquid phases.

\subsubsection{Conversion in gas phase}

To discriminate the effect of the hydroxyl groups from the one of carbonates the transesterification model reaction was operated on magnesium oxide for the three different surfaces (see section 3.1.1).

Figure 3 shows the conversions of ethyl acetate into methyl acetate in gas phase as function of temp. As for the isomerization of hept-1-ene, the conversion at low pretreatment temperature is small for all the pretreatments. Within the reproducibility of the measurements $( \pm 3 \%)$, the conversion for the transesterification on magnesium oxide at "temp" $=1023 \mathrm{~K}$ was similar for the three kinds of pretreatments. Hence, the same clean surface is recovered at high temperature, insuring an acceptable reversibility of the hydroxylation and carbonation pretreatments.

In the case of the hydroxylated and carbonated surfaces, a monotonic increase of the reactivity with the pretreatment temperature is observed. Therefore, a simple link exists between the adsorbates coverage and the reactivity: when fewer adsorbates are on the surface, better is the reactivity. Hydroxyl groups and carbonates are therefore poisoning the surface, inhibiting probably the reactants adsorption. The surface reconstruction of the hydroxylated surface doesn't seem there to improve the reactivity. Steps, corners, kinks, and divacancies, that are progressively desorbed, in this range of temperature, from hydroxyls and carbonates ${ }^{[13]}$, are probable sites for this reaction. 
For the natural surface, a maximum of conversion is obtained for a pretreatment temperature of $623 \mathrm{~K}$ and this behaviour is similar to the one observed in the hept-1ene conversion. Nevertheless, the maximum for hept-1-ene conversion is obtained for a catalyst pretreated at a temperature $150 \mathrm{~K}$ higher than for transesterification. Furthermore, the maximum conversion value reached in transesterification is almost 1.5 times the best conversion obtained on hydroxylated or carbonated surfaces.

From these results, it can be concluded that there is no direct correlation between basicity and reactivity in gas phase transesterification as two very basic surfaces, the natural and the hydroxylated, pretreated at $773 \mathrm{~K}$, are not the most reactive. Moreover, no decrease of the reactivity with high temperature pretreatment is observed, thus, the highly basic (110) unstable planes are probably not the best sites and it must be considered that the usual $\mathrm{MgO}$ (100) defects revealed upon desorption of the natural adsorbates exhibit the highest activity.

The very high activity observed for the natural surface pre-treated at $623 \mathrm{~K}$ can be linked to specific defects formation, unidentified at that date. $\mathrm{IR} / \mathrm{CO}_{2}$ has evidenced, on this system, the more abundant formation of (110) planes than on the hydroxylated surface but this restructuration may be accompanied by others unstable defects formation. The coexistence of carbonates and hydroxyl groups on this surface, after a long time atmosphere exposure may also explain the obtention of a transient very disordered surface. However, further work is necessary to have a better description of this very reactive surface.

\subsubsection{Conversion in liquid phase}

Transesterification in liquid phase was only studied on $\mathrm{MgO}$ natural surface and the catalytic data as function of the pretreatment temperature (temp) are given Figure 4 
(dashed line) after 5 hours of reaction time. The general trend is close to the one observed in the gas phase, also reported for comparison on Figure 4: for low pretreatment temperature, the conversion improves when the pretreatment temperature increases. At high pretreatment temperature, the reverse behavior is observed, even if the conversion remains high. Nevertheless, the best pretreatment temperature is not the same in gas phase $(623 \mathrm{~K})$ and in liquid phase $(773 \mathrm{~K})$. It is highlighted that this latter value is similar to the one observed for hept-1-ene isomerization. It can be inferred that in the liquid phase, the strong basic sites created on the (110) unstable planes play an important role in the catalytic performance.

\subsubsection{Link with basicity}

According to Dossin et al. ${ }^{[16]}$ the mechanism of the transesterification of methanol with ethyl acetate in the liquid phase follows an Eley-Rideal mechanism with adsorbed methanol. A Langmuir-Hinshelwood-Hougen-Watson mechanism was found by Kapil et al. ${ }^{[41]}$ in the case of triglycerides transesterification on basic hydrotalcites methanol adsorption, This mechanism also involve the adsorption of methanol as rate determining step. It is not thus surprising that the trend observed for the basicity measured through the hept-1-ene isomerization model reaction is the same as the one found for the transesterification in liquid phase and that a maximum for the conversion is reached for a temperature around $773 \mathrm{~K}$. Nevertheless, at low pretreatment temperature, the conversion for transesterification in liquid phase occurs as no conversion of hept-1-ene is observed. This has to be linked with the huge difference in residence time between liquid and gas phase, which forbids any direct comparison between the conversions. 
Therefore, in liquid phase, the trend mentioned in the introduction, "the more basic the surface, the better the catalyst for transesterification" is here verified with the model reaction of isomerization of alkene as scale of basicity.

For the gas phase transesterification, the behavior of the catalysts is different from the one obtained in hept-1ene isomerization: no maximum of transesterification activity is observed for the hydroxylated surfaces nor for natural surfaces (Figure 3), the best catalyst for these two reactions is obtained for different pretreatment temperatures (623 vs $773 \mathrm{~K})$. The highly basic (110) planes don't seem to play a key role in transesterification reaction.

To our knowledge, there is no data in the literature concerning the heterogeneously catalyzed mechanism of the transesterification reaction in gas phase, but from this study it can be suggested that the mechanism to be considered may not involve adsorption of the methanol as a rate determining step.

In order to go deeper in the comprehension of the characteristics of the surface that are needed to catalyze the transesterification reaction, the dynamic adsorption of the methanol that is the major component of the reacting flow was investigated.

\subsubsection{Dynamic adsorption of methanol}

In order to measure the capacity of the oxide to adsorb methanol in similar conditions to those of the catalysis in gas phase (that is to say from gas flow containing nitrogen and reactive molecules), dynamic adsorption of methanol on natural surfaces of magnesium oxide was carried out. The integration of the difference between the concentration of the methanol measured after the introduction on a blank and a $\mathrm{MgO}$ filled reactor gives the total amount of methanol molecules adsorbed (physisorbed or 
chemisorbed) on the surface. This method is inspired by the "Breakthrough methods" used, for instance, in environmental remediation. ${ }^{[42]}$

Figure 4 indicates the total adsorption of methanol in $\mu$ mol.g $\mathrm{g}^{-1}$ on the natural surface as a function of pretreatment temperatures temp (dotted line). The amount of adsorbed methanol varies with temp: a maximum capacity to adsorb methanol is observed for the sample pretreated at $773 \mathrm{~K}$. The maximal value of around $175 \mu \mathrm{mol} . \mathrm{g}^{-1}$ of methanol adsorbed on the surface is in agreement with the amount found in $\mathrm{IR} / \mathrm{CO}_{2}$ experiments, necessary to saturate the adsorption sites (result not shown).

The conversion obtained in the transesterification in liquid phase follows the same trend than the total adsorption of methanol that can be adsorbed on this surface (figure 4). It is a new hint to consider the adsorption of methanol as the rate determining step, as considered by Dossin ${ }^{[16]}$. However, for the gas phase, there is no direct correlation between the methanol adsorption capacity and the catalysis of the reaction, in agreement with the lack of correlation, already reported, between the catalytic transesterification activity and the basicity.

\subsection{Discussion on the reaction intermediates and DFT calculations.}

From these results it may be inferred that the transesterification reaction mechanism differs from the liquid to the gas phase. The overall route may be the same with a different rate determining step or the route itself is different. As, in the liquid phase, our conclusions are in agreement with literature data concerning the identification of the rate determining step as the methanol adsorption, we tried to give some insights on how the reactants could be adsorbed on the $\mathrm{MgO}$ surface in gas phase. 
Adsorption of methanol on the defects of the $\mathrm{MgO}$ (100) surface has already been calculated by DFT in our group ${ }^{[35]}$ and results were consistent with the previous DFT work of Rodriguez et al. on the adsorption of this alcohol over the (100) plane ${ }^{\text {[43] }}$ and on the edges. ${ }^{[4]}$ Some studies were also performed about the adsorption of fatty acid methyl ester, ${ }^{[23,27,45,46]}$ but the adsorption of small ester on $\mathrm{MgO}$ was, to our knowledge never investigated. Moreover, most of the studies concerning the activation of the ester only considered a kind of Lewis adduct between the oxygen of the $\mathrm{C}=\mathrm{O}$ bond of the ester and a magnesium cation of the surface. Nevertheless, other activations of the ester are possible and often neglected, for instance, the deprotonation of the ester, as suggested by the mass spectrometry study of Haas et al. ${ }^{[47]}$ : they show that in vacuum conditions the transesterification reaction involves a deprotonated ester instead of a deprotonated alcohol (scheme 2). ${ }^{[47]}$

In order to evaluate the adsorption mechanisms of acetyl acetate on $\mathrm{MgO}$ defects we calculated the minimum energy structures of adsorbed ester, deprotonated or not, interacting with a monoatomic step. DFT adsorption energies and optimized geometric parameters are reported in table 1. Figure 5 illustrates the adsorption modes of the modelled ester on the $\mathrm{MgO}$ (100) step. The data for formic acid chelated to $\mathrm{Mg}^{2+}$ were used for a comparison. For the ester adsorbed on the step, the distance between the magnesium cation and the $\mathrm{O}$ atom from the $\mathrm{C}=\mathrm{O}$ bond $(2.10 \AA)$ is slightly higher than for the one found for the chelation of $\mathrm{a}^{2+}$ cation by a carboxylic acid (1.85 $\left.\mathrm{A}\right)$. This difference is related to the steric repulsion of the other atoms from the surface. ${ }^{[48]}$ This longer distance may explain the much less exothermic adsorption of the non deprotonated ester on the step $(-0.44 \mathrm{eV})$ compared to the formic acid coordinated with a single $\mathrm{Mg}^{2+}$ cation $(-4.33 \mathrm{eV})$. 
When the ester is deprotonated, the adsorption becomes far more favored (-1.27 $\mathrm{eV})$. This is due to the strong binding between the proton coming from the methyl group with an oxygen ion from the surface and to the better interaction between the surface and the oxygen, more negatively charged when the ester is deprotonated.

As shown by DFT calculations, the deprotonation of the ester stabilizes its adsorption on the catalyst. Due to this increased stability the deprotonation energy for the ester is closer to the one of the methanol $(-1.86 \mathrm{eV}) .{ }^{[35]}$ This preliminary result indicates that the endothermicity of the $\mathrm{C}-\mathrm{H}$ bond breaking is in this case compensated by the creation of bond with the support. Of course further mixed experimental theoretical studies are needed to determine whether the thermodynamically favored methanol dissociation (specially when methanol is introduced in large excess) may compete kinetically with the ester dissociation to perform the overall reaction. But these results show that a mechanism involving a deprotonated ester must be a considered way to describe the reaction pathway of the transesterification on $\mathrm{MgO}$ in the gas phase, among other possibilities of ester activation as those shown by Gómez-Bombarelli for the hydrolysis of ester. ${ }^{[49]}$ Finally, the prediction given by our preliminary DFT calculations of the phenomena occurring around the active site would be less representative in liquid phase as the solvent is not taken into account and thus, may change the stabilization of the intermediate products.

\section{Conclusion}

The impact of the basicity of solids in their ability to catalyze transesterification differs between the liquid and the gas phase.

- In liquid phase: Natural surfaces of magnesium oxide pretreated at a temperature of $773 \mathrm{~K}$ are the most active catalyst for the 
transesterification. Due to the transient formation of (110) planes this surface is also the most basic surface according to both model reaction of basicity and to the dynamic adsorption of methanol on its surface. The link between basicity and reactivity is confirmed and backed by the proposed mechanisms for this reaction.

- In gas phase: The link between basicity and reactivity is not obvious any more, as two very basic surfaces, the natural and the hydroxylated, pretreated at $773 \mathrm{~K}$, are not the most reactive ones. Obviously, the formation of highly basic (110) planes is not a key parameter in this case. The best catalysts are obtained upon desorption of the natural adsorbates of the surface that exhibit the usual $\mathrm{MgO}$ (100) defects. The very high activity observed for the natural surface pre-treated at $623 \mathrm{~K}$ can be linked to deep reconstruction of the material after a long time atmosphere exposure that lead to transient very disordered surface. The mechanism has to be studied in order to explain these results. As shown by DFT calculations, the deprotonated ester may be a legitimate first reaction intermediate. 


\section{References}

(1) Gaurav, K.; Srivastava, R.; Singh, R. International Journal of Green Energy 2013, 10, 775-796.

(2) Xu, J.; Wu, H.-T.; Ma, C.-M.; Xue, B.; Li, Y.-X.; Cao, Y. Applied Catalysis A: General 2013, 464, 357-363.

(3) Manzer, L. E. Synthesis Of Alkenoate Esters From Lactones And Alcohols. WO 2004007421 A1, January 22, 2004.

(4) Koseva, N.; Kurcok, P.; Adamus, G.; Troev, K.; Kowalczuk, M. Macromolecular Symposia 2007, 253, 24-32.

(5) Woodruff, M. A.; Hutmacher, D. W. Progress in Polymer Science 2010, 35, 1217-1256.

(6) Bancquart, S.; Vanhove, C.; Pouilloux, Y.; Barrault, J. Applied Catalysis A: General 2001, 218, 1-11.

(7) Sandesh, S.; Shanbhag, G. V.; Halgeri, A. B. Catalysis Letters 2013, 143, 12261234.

(8) Fraile, J. M.; García, N.; Mayoral, J. A.; Pires, E.; Roldán, L. Applied Catalysis A: General 2009, 364, 87-94.

(9) Frey, A. M.; Yang, J.; Feche, C.; Essayem, N.; Stellwagen, D. R.; Figueras, F.; De Jong, K. P.; Bitter, J. H. Journal of Catalysis 2013, 305, 1-6.

(10) Hayashi, J.; Xu, G.; Li, C.-Z.; Castro, C. S.; Ferreti, C.; Di Cosimo, J. I.; Assaf, J. M. Fuel 2013, 103, 632-638.

(11) Faungnawakij, K.; Yoosuk, B.; Namuangruk, S.; Krasae, P.; Viriya-empikul, N.; Puttasawat, B. ChemCatChem 2012, 4, 209-216.

(12) Domínguez, D. J.-M.; Wang, D. J.-A.; Sedran, D. U.; Manríquez-Ramírez, M.; Gómez, R.; Hernández-Cortez, J. G.; Zúñiga-Moreno, A.; Reza-San Germán, C. M.; Flores-Valle, S. O. Catalysis Today 2013, 212, 23-30.

(13) Cornu, D.; Guesmi, H.; Krafft, J.-M.; Lauron-Pernot, H. The Journal of Physical Chemistry C 2012, 116, 6645-6654.

(14) Veiga, P. M.; Sousa, Z. S. B.; Polato, C. M. S.; Portilho, M. F.; Veloso, C.; \#xe1; O., U.; Henriques, C. A. Journal of Catalysts 2013, 2013, 685063.

(15) Kozlowski, J. T.; Aronson, M. T.; Davis, R. J. Applied Catalysis B: Environmental 2010, 96, 508-515.

(16) Dossin, T. F.; Reyniers, M.-F.; Marin, G. B. Applied Catalysis B: Environmental 2006, 62, 35-45. 
(17) Navajas, A.; Arzamendi, G.; Romero-Sarria, F.; Centeno, M. A.; Odriozola, J. A.; Gandía, L. M. DRIFTS study of methanol adsorption on $\mathrm{Mg}-\mathrm{Al}$ hydrotalcite catalysts for the transesterification of vegetable oils. Catalysis Communications 2012, 17, 189-193.

(18) Maniatis, K.; Chiaramonti, D.; Kumar, D.; Ali, A. Biomass and Bioenergy 2012, 46, 459-468.

(19) Greenwell, H. C.; Stackhouse, S.; Coveney, P. V.; Jones, W. The Journal of Physical Chemistry B 2003, 107, 3476-3485.

(20) Hattori, H.; Shima, M.; Kabasjima, H. Studies in Surface Science And Catalysis 20003507 2000, 130D, 3507-3512.

(21) Manzer, L. E. Applied Catalysis A: General 2004, 272, 249-256.

(22) Lauron-Pernot, H. Evaluation of Surface Acido-Basic Properties of InorganicBased Solids by Model Catalytic Alcohol Reaction Networks 2006, 48, 315-361.

(23) Ferretti, C. A.; Fuente, S.; Ferullo, R.; Castellani, N.; Apesteguía, C. R.; Di Cosimo, J. I. Applied Catalysis A: General 2012, 413-414, 322-331.

(24) Xu, C.; Enache, D. I.; Lloyd, R.; Knight, D. W.; Bartley, J. K.; Hutchings, G. J. Catalysis Letters 2010, 138, 1-7.

(25) Pacchioni, G.; Freund, H. Chemical reviews 2012, 4035-4072.

(26) Geysermans, P.; Finocchi, F.; Goniakowski, J.; Hacquart, R.; Jupille, J. Physical chemistry chemical physics: PCCP 2009, 11, 2228-33.

(27) Cosimo, J. I. D.; K. Díez, V.; C. Ferretti; R. Apesteguía, C. Catalysis; Spivey, J.; Han, Y.-F.; Dooley, K., Eds.; Royal Society of Chemistry: Cambridge, 2014; Vol. 26, pp. 1-28.

(28) Bailly, M.-L.; Chizallet, C.; Costentin, G.; Krafft, J.-M.; Lauron-Pernot, H.; Che, M. Journal of Catalysis 2005, 235, 413-422.

(29) Cornu, D.; Petitjean, H.; Costentin, G.; Guesmi, H.; Krafft, J.-M.; Lauron-Pernot, H. Physical chemistry chemical physics : PCCP 2013, 15, 19870-8.

(30) Bailly, M.-L.; Costentin, G.; Lauron-Pernot, H.; Krafft, J. M.; Che, M. The journal of physical chemistry. B 2005, 109, 2404-13.

(31) Kresse, G.; Hafner, J. Physical Review B 1993, 47, 558-561.

(32) Kresse, G.; Furthmüller, J. Computational Materials Science 1996, 6, 15-50.

(33) Perdew, J.; Wang, Y.; Engel, E. Physical Review Letters 1991, 66, 508-511. 
(34) Chizallet, C.; Costentin, G.; Che, M.; Delbecq, F.; Sautet, P. The Journal of Physical Chemistry B 2006, 110, 15878-15886.

(35) Petitjean, H.; Tarasov, K.; Delbecq, F.; Sautet, P.; Krafft, J. M.; Bazin, P.; Paganini, M. C.; Giamello, E.; Che, M.; Lauron-Pernot, H.; Costentin, G. The Journal of Physical Chemistry C 2010, 114, 3008-3016.

(36) Chizallet, C.; Costentin, G.; Che, M.; Delbecq, F.; Sautet, P. Journal of the American Chemical Society 2007, 129, 6442-6452.

(37) Spagnoli, D.; Allen, J. P.; Parker, S. C. Langmuir : the ACS journal of surfaces and colloids 2011, 27, 1821-9.

(38) Evans, J. V; Whateley, T. L. Transactions of the Faraday Society 1967, 63, 2769-2777.

(39) Hacquart, R.; Jupille, J. Journal of Crystal Growth 2009, 311, 4598-4604.

(40) Leclercq, E.; Finiels, A.; Moreau, C. Journal of the American Oil Chemists' Society 2001, 78, 1161-1165.

(41) Kapil, A.; Wilson, K.; Lee, A. F.; Sadhukhan, J. Industrial \& Engineering Chemistry Research 2011, 50, 4818-4830.

(42) Taty-Costodes, V. C.; Fauduet, H.; Porte, C.; Ho, Y.-S. Journal of hazardous materials 2005, 123, 135-44.

(43) Rodriguez, A. H.; Branda, M. M.; Castellani, N. J. Journal of Physical Chemistry C 2007, 111, 10603-10609.

(44) Rodríguez, A. H.; Branda, M. M.; Castellani, N. J. Journal of Molecular Structure: THEOCHEM 2006, 769, 249-254.

(45) Cesar Huppes da Silva, A.; Claudino da Silva, S.; Dall'Oglio, E. L.; De Sousa, P. T.; Alberto Kuhnen, C. Fuel 2013, 104, 379-385.

(46) Yu, K.; Schmidt, J. R. The Journal of Physical Chemistry C 2011, 115, $1887-$ 1898.

(47) Haas, G. W.; Giblin, D. E.; Gross, M. L. International Journal of Mass Spectrometry and Ion Processes 1998, 172, 25-46.

(48) Remko, M. Journal of Molecular Structure: THEOCHEM 2000, 505, 269-281.

(49) Gómez-Bombarelli, R.; Calle, E.; Casado, J. The Journal of organic chemistry 2013, 78, 6868-79.

(50) Bagno, A.; Scorrano, G. The Journal of Physical Chemistry 1996, 100, 15361544. 
Table 1

Energy and geometrical parameters for esters and acids bounded to $\mathrm{Mg}^{2+}$ ions calculated by DFT and comparison with experimental data ${ }^{[50]}$

\begin{tabular}{|c|c|c|c|c|}
\hline & Eads (eV) & $\mathrm{C}-\mathrm{H}(\AA)$ & $\mathrm{Mg}-\mathrm{O}(\AA)$ & $\mathrm{Mg}-\mathrm{O}-\mathrm{C}\left(^{\circ}\right)$ \\
\hline $\begin{array}{c}\text { Formic acid } \\
\text { chelating } \mathrm{Mg}^{2+[50]}\end{array}$ & -4.33 & 1.10 & 2.10 & 161 \\
\hline $\begin{array}{c}\text { Non-deprotonated } \\
\text { ester on MgO step }\end{array}$ & -0.44 & 3.87 & 2.00 & 134 \\
\hline $\begin{array}{c}\text { Deprotonated ester } \\
\text { on MgO step }\end{array}$ & -1.27 & & \\
\hline
\end{tabular}


Scheme 1

Plausible mechanism for the transesterification with deprotonation of the alcohol

1

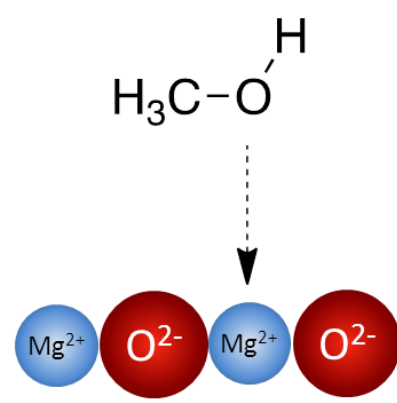

3

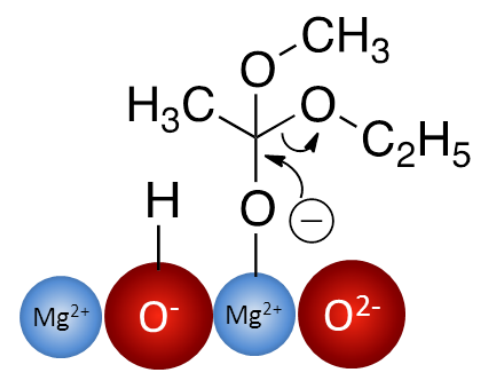

2

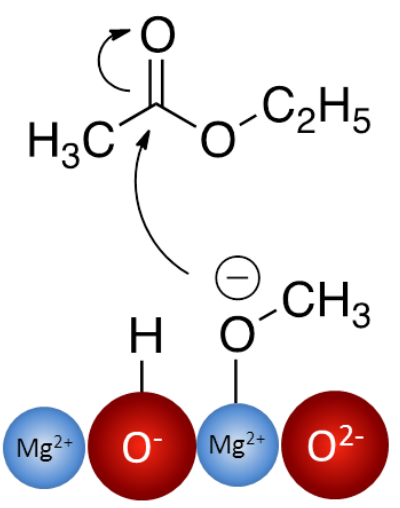

4<smiles>COC(C)=O</smiles>

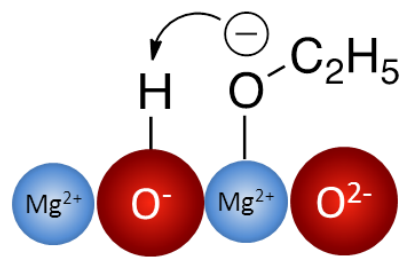


Scheme 2

Plausible mechanism for the transesterification with deprotonation of the ester based on [47]

1

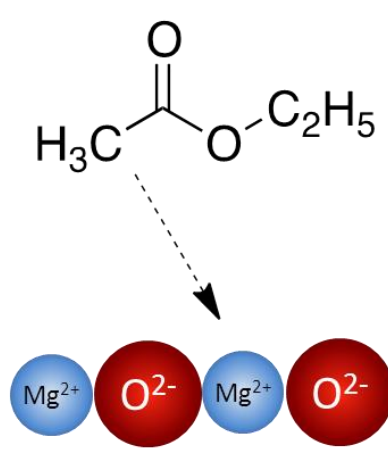

3

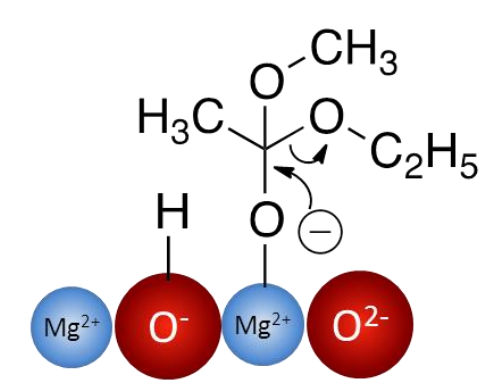

2

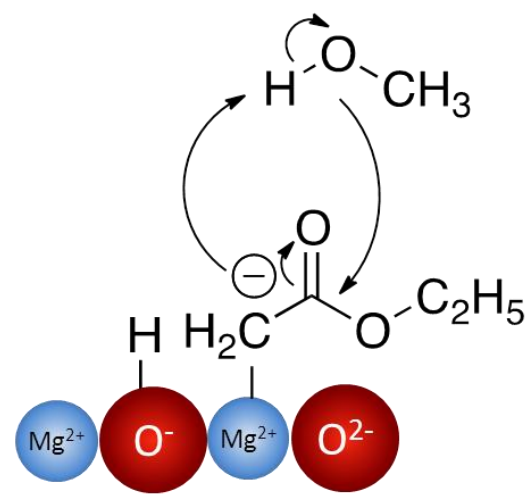

4

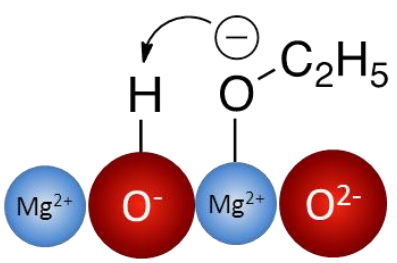


Figure 1

Reactivity of hydroxylated, carbonated and natural $\mathrm{MgO}$ surfaces in hept-1-ene isomerization as a function of pretreatment temperature. The results for the hydroxylated and the carbonated surfaces were already published in ${ }^{[29]}$

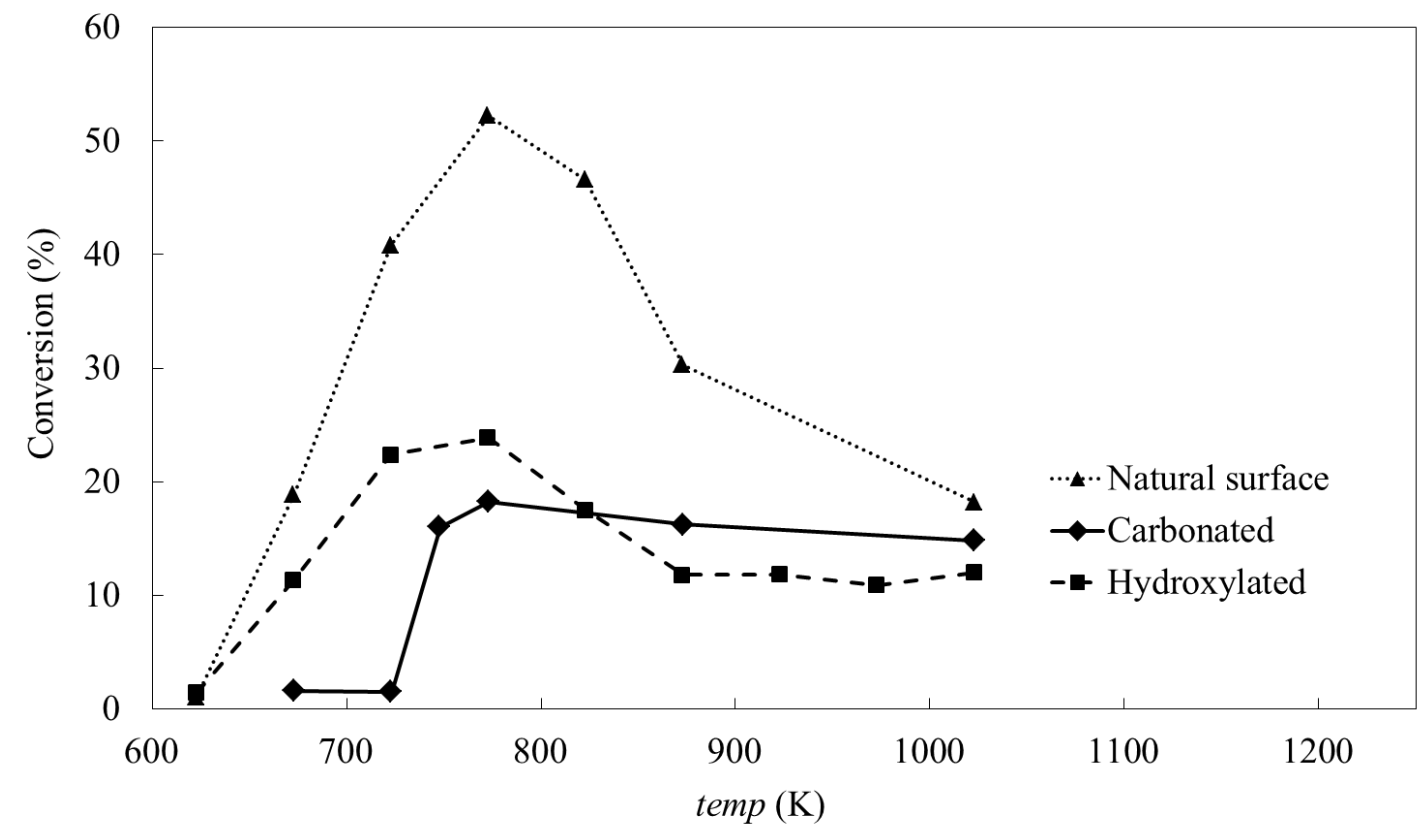




\section{Figure 2}

FTIR spectra of natural $\mathrm{MgO}$ surfaces at temp $=773 \mathrm{~K}$ (dashed line) and $1023 \mathrm{~K}$ (solid line) registered at room temperature after addition of $14 \mu \mathrm{mol}$ (a) and $56 \mu \mathrm{mol}$ (b) of $\mathrm{CO}_{2}$ per gram of catalyst.

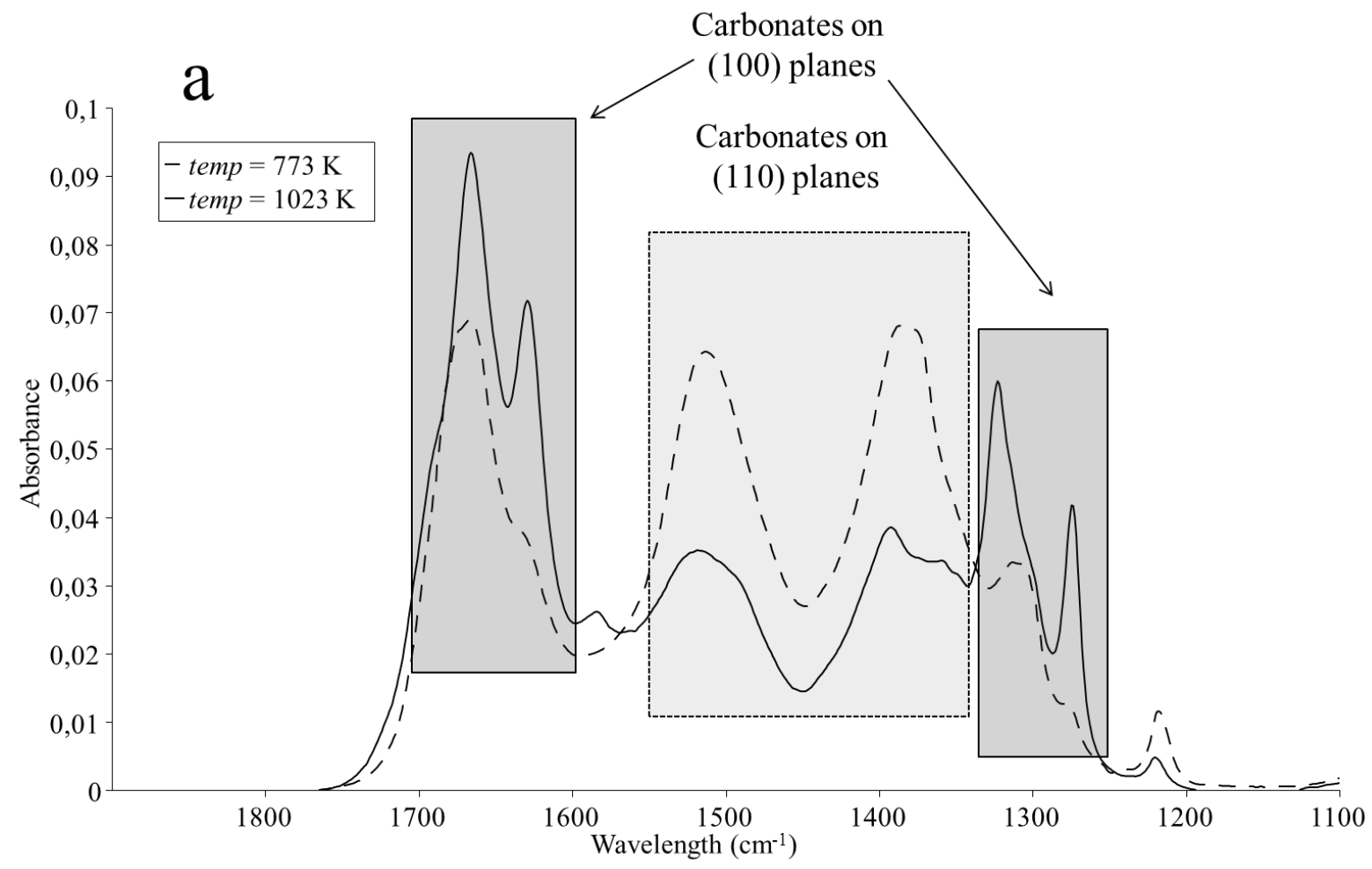


b

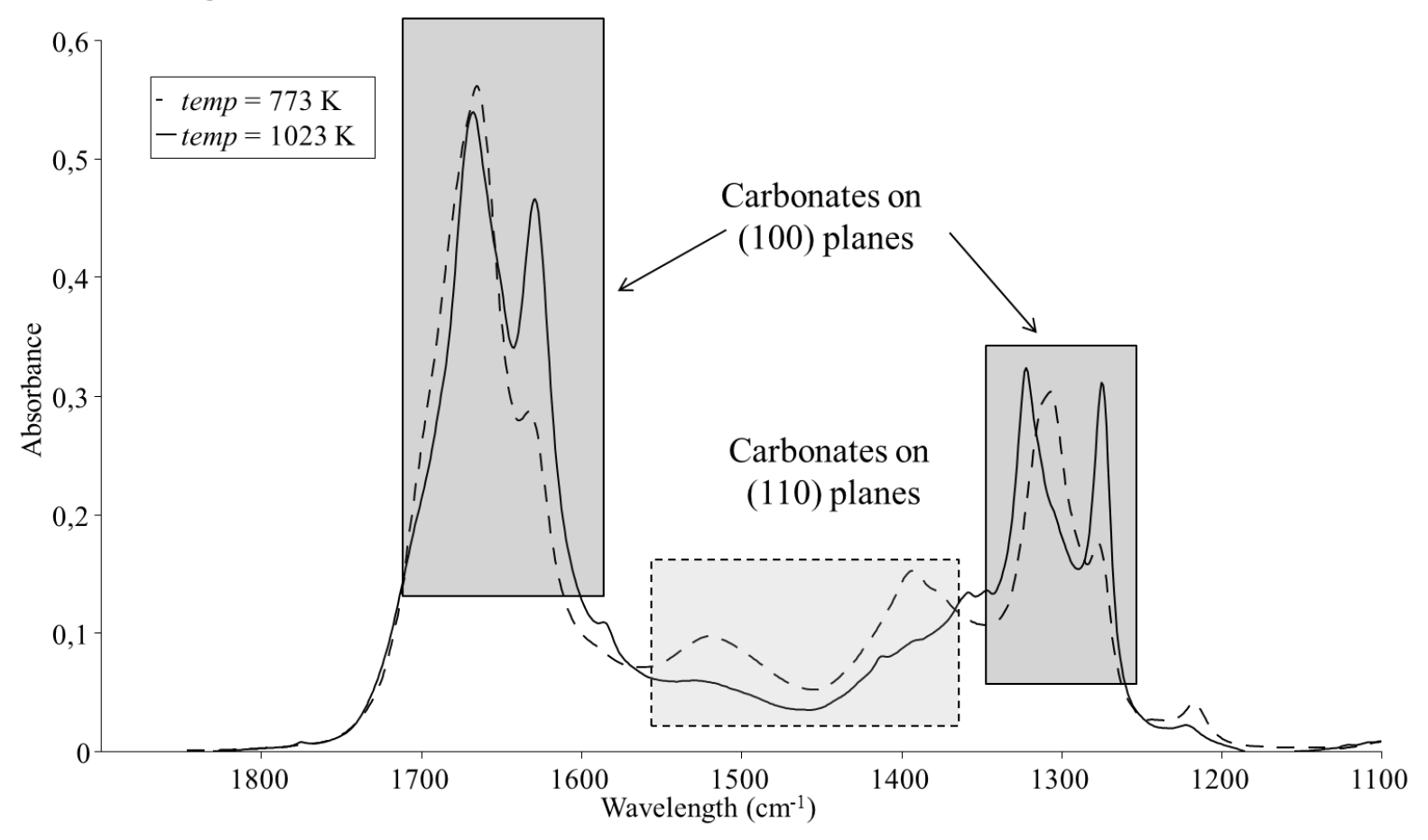




\section{Figure 3}

Reactivity of $\mathrm{MgO}$ in the transesterification reaction in gas phase after different kinds of pretreatment as a function of temp

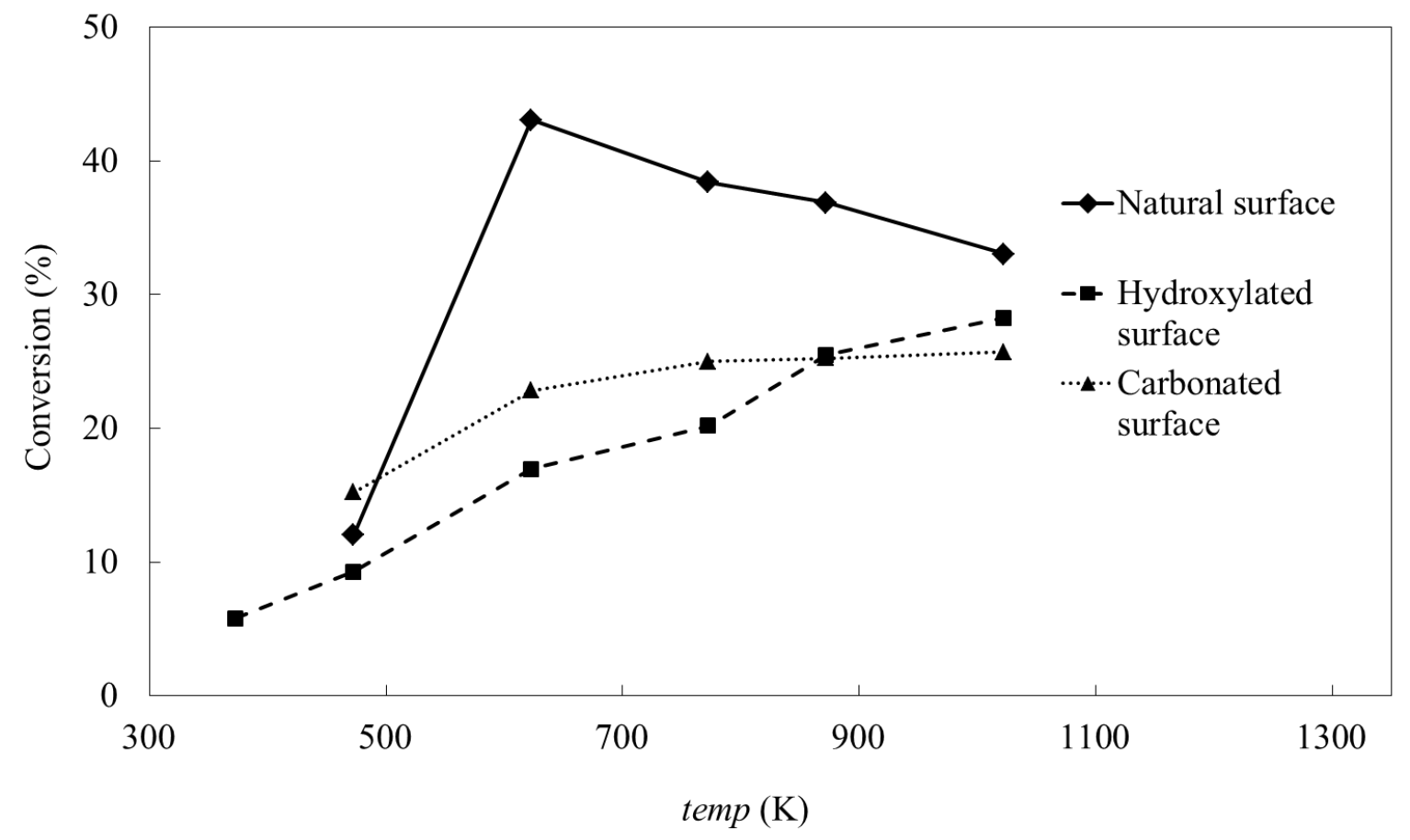




\section{Figure 4}

Amount of $\mathrm{MeOH}$ molecules adsorbed on $\mathrm{MgO}$ natural surface (left scale, dotted curve) and transesterification conversion (right scale) in liquid (dashed line) and gas (solid line) phases as a function of the pretreatment temperature.

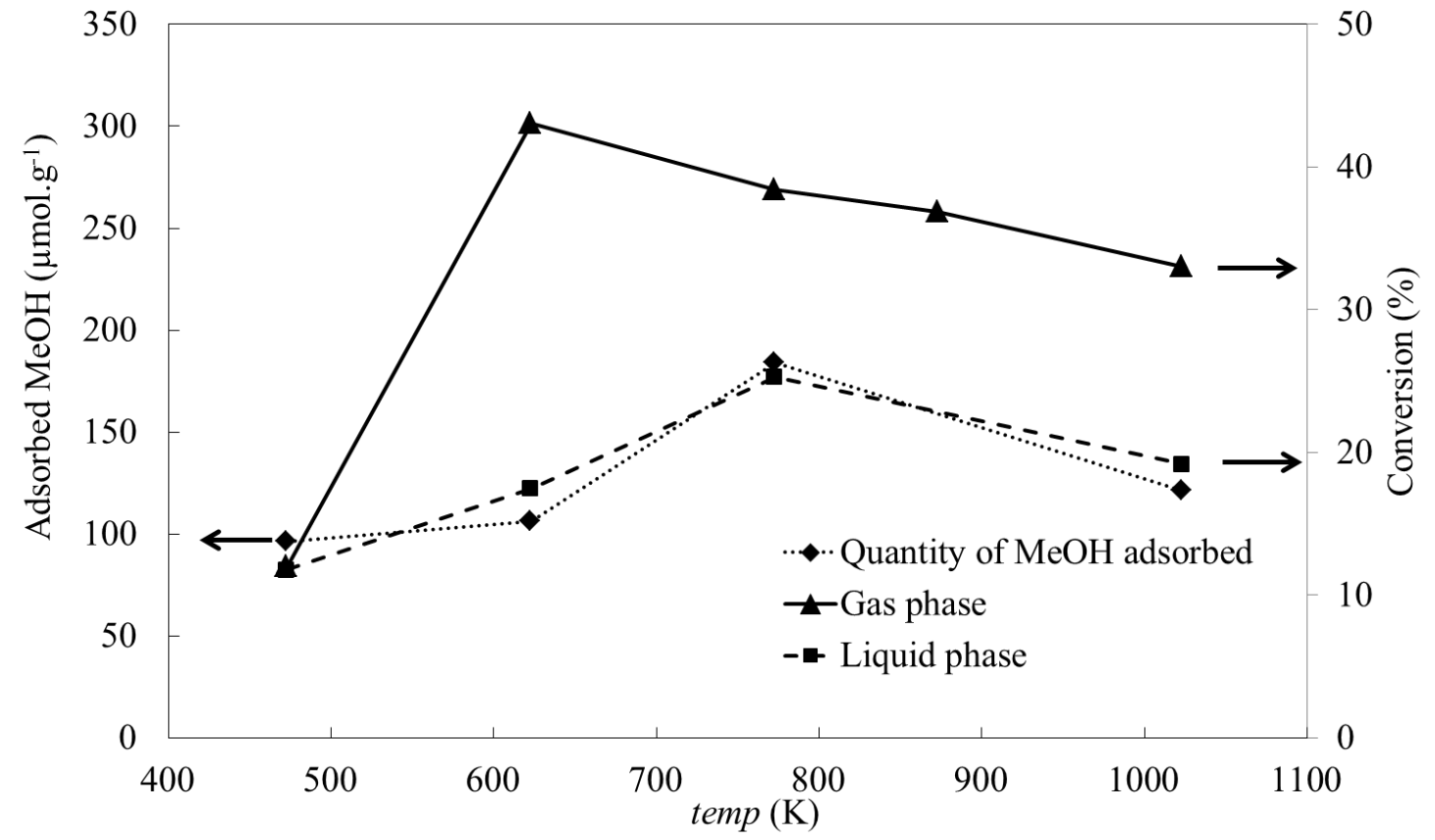




\section{Figure 5}

DFT optimized structures of the ester molecule adsorbed on a $\mathrm{MgO}$ (100) step, before and after methyl group deprotonation . a) protonated ester, b) deprotonated ester
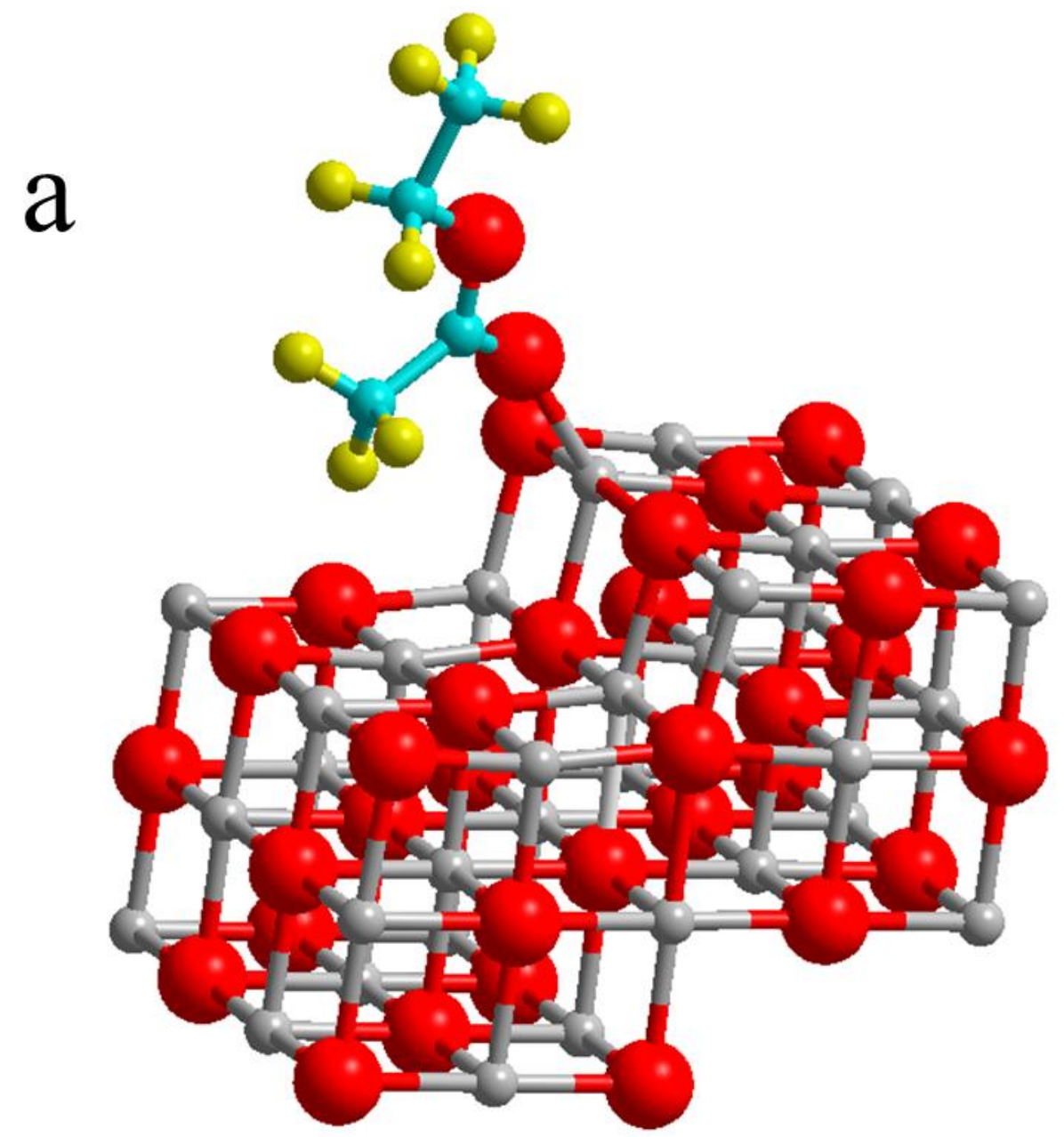


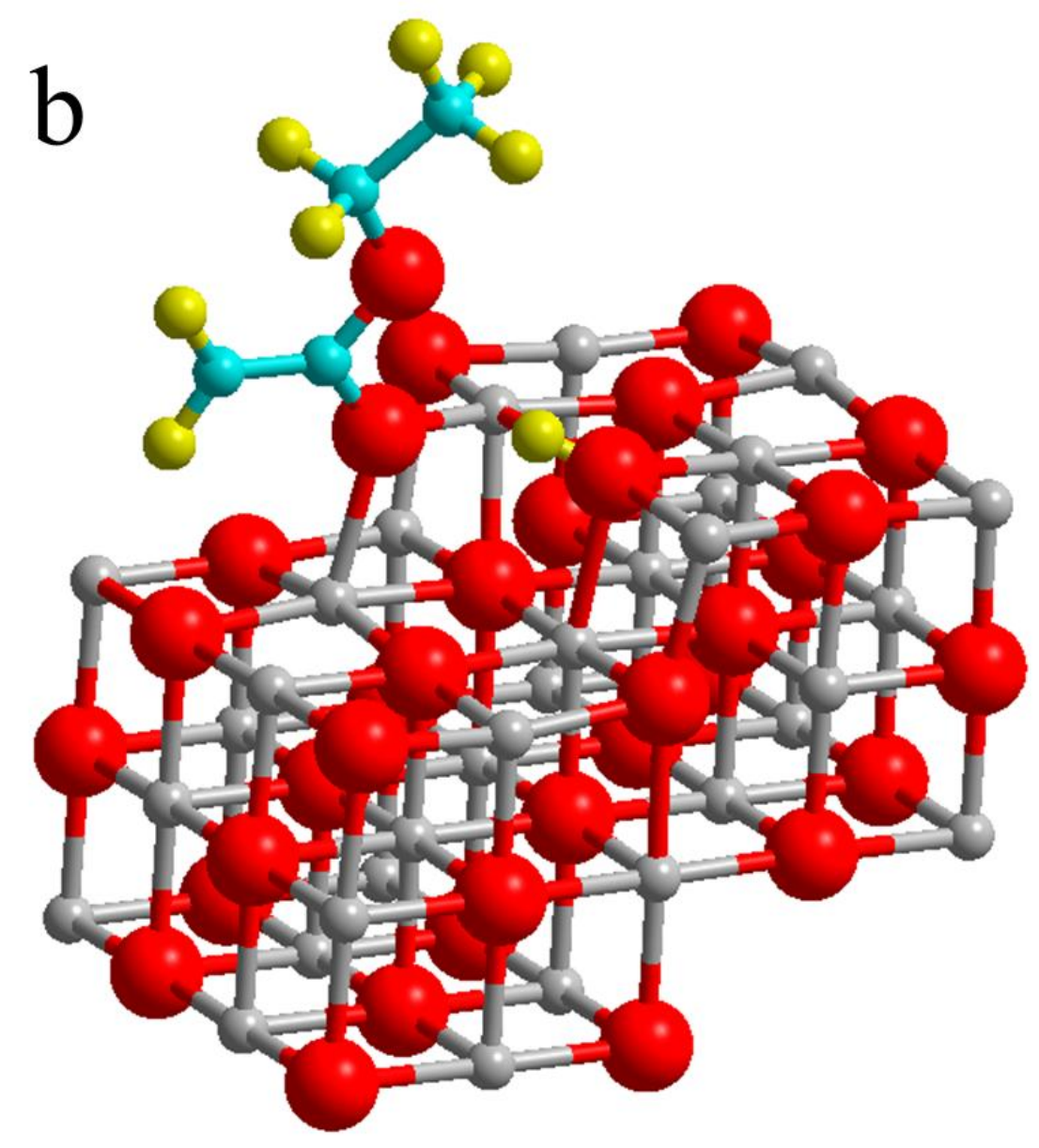

